\title{
Motor Imagery Experiences and Use: Asking Patients after Stroke Where, When, What, Why, and How They Use Imagery: A Qualitative Investigation
}

\author{
Corina Schuster, ${ }^{1,2}$ Andrea Glässel, ${ }^{3,4}$ Anne Scheidhauer, ${ }^{1}$ Thierry Ettlin, ${ }^{1,5}$ \\ and Jenny Butler ${ }^{2}$ \\ ${ }^{1}$ Research Department Reha Rheinfelden, Salinenstrasse 98, 4310 Rheinfelden, Switzerland \\ ${ }^{2}$ Department of Sport and Health Sceinces, Faculty of Health and Life Sciences, Oxford Brookes University, Oxford OX3 OBP, UK \\ ${ }^{3}$ Institute of Health and Rehabilitation Sciences, Ludwig-Maximilians-University Munich, 80539 Munich, Germany \\ ${ }^{4}$ Faculty of Social Work and Health, University of Applied Sciences and Arts, 31134 Hildesheim, Germany \\ ${ }^{5}$ Department of Behavioural Neurology, Medical faculty, University of Basel, 4053 Basel, Switzerland \\ Correspondence should be addressed to Corina Schuster, c.schuster@reha-rhf.ch
}

Received 3 October 2011; Revised 11 January 2012; Accepted 16 January 2012

Academic Editor: Steven L. Wolf

Copyright ( $\odot 2012$ Corina Schuster et al. This is an open access article distributed under the Creative Commons Attribution License, which permits unrestricted use, distribution, and reproduction in any medium, provided the original work is properly cited.

\begin{abstract}
Background. A framework on where, when, what, why, and how to use imagery from sports psychology was explored whether it can be applied in patients after stroke in their chronic stage. Methods. Eleven patients (ages 31-85, 3 females, 1.3-6.4 years after stroke) were interviewed. Semistructured interviews were conducted before and after a two-week MI intervention period with six MI sessions. Information was obtained regarding experiences and knowledge of MI, and the evaluation of an MI practical example. The coding scheme was based on the framework and a hierarchical categorisation. Results. Information regarding domains where, when, what, why, and how to use imagery was addressed. Patients imagined themselves as healthy individuals, did not focus on surroundings during MI practice,and reported to use positive imagery only. After MI training, patients became more flexible regarding their location and position during MI practice. Conclusions. MI became an automatic process, and patients did not need specific concentration and quietness as mentioned in the first interview. Patients recommended daily MI training and began to transfer MI to practice movements that were affected by the stroke. In contrast to sports, patients did not talk about how MI was triggered rather than how MI was designed.
\end{abstract}

\section{Introduction}

Motor imagery (MI) is a recognised and established method for different individuals (children, students, athletes, and patients) and for different purposes (cognitive, strength, and motor-related tasks). During recent years, MI has received increasing attention as a training approach in rehabilitation of stroke patients [1-4]. However, designing effective imagery interventions depends on patients' typical normal use, intentions, and imagery content when using the technique. Currently, patient experiences and meanings attributed to MI are widely unknown so far.

After adopting MI in stroke rehabilitation in the late 1990s, it has been shown to be beneficial for motor function recovery when added to physical practice $[1,2]$. Decety and Grezes have defined MI as "...a dynamic state during which the representation of a given motor act is internally rehearsed within working memory without any overt motor output" [5]. Research has been performed investigating different techniques of MI and their effect on both motor function and psychological parameters [6-8].

In psychology, the influential work of Kosslyn et al. moved the research perspective from applying MI in interventions with individuals to research in the natural occurrences and use of MI in everyday life [9]. The authors asked twelve undergraduate student volunteers to keep an imagery diary for one week and note down when and where imagery had been used. Students had to describe the situation they were in 
when imagery occurred, the content of what has been imagined, and the vividness of the image. Furthermore, authors wanted to know why individuals had used imagery and what the intention to use imagery in the current situation was. Additionally, students had to define their understanding of a "mental image." Study results were analysed regarding the categories modality, purpose, and content of imagery. It could be shown that visual and auditory imagery modes were mostly reported. The category purpose included six types: more than half of the study population reported associative (e.g., day dreaming), problem solving (e.g., mental maps to navigate), mental practice (e.g., imagine swimming stroke), memory recall (e.g., imagine notes during test), comprehending descriptions (e.g., image based on verbal description), and emotional or motivational stimulus (e.g., to calm down), as imagery content coloured and concrete (vivid) images were the most frequent reported ones. In the same paper, they described a second study on imagery every day use that confirmed the findings of the first experiment for all three categories: modality, purpose, and content [9].

Ten years later, Munroe et al. used semistructured indepth interviews in 14 athletes from various disciplines to find answers on where, when, whym and what imagery has been used. Obtained information had been structured according to these 4-Wquestions. In addition, information on why using imagery had been structured according to Paivio's framework on effects of imagery on human motor performance $[10,11]$. In this framework, Paivio [11] suggested two main functions of imagery (cognitive, motivational) that work on a general level, for example, cognitive general and motivational general, or specific level, comprising cognitive specific and motivational specific types. Motivational functions are used to reduce anxiety or increase self-confidence. Cognitive functions, for example, attention, enable athletes to use different imagery perspectives and to transfer the imagine tasks to competitive situations. However, for the current investigation, it will be interesting if patients after stroke will address both aspects from their personal experience. In the patients' case, "competitive situations" could be related to movements, tasks, or settings that are challenging due to motor function limitations. Furthermore, Paivio's findings influenced Munroe et al.'s results classification for athletes imagery use: during and outside practice, for precompetition, competition, and postcompetition. Furthermore, their analysis on imagery content included type (visual, kinaesthetic) and perspective (internal, external) of MI.

In 2005, Nordin and Cumming interviewed 14 professional dancers to describe their imagery use [12]. Again, information was categorised according to the 4-W-questions: where, when, why, and what have been imagined. In their analysis, a new domain has emerged on how images were obtained. This domain included three categories: external stimuli, retrieving memories, and creating triggers.

Moving away from healthy students and athletes, Driediger et al. investigated athletes with musculoskeletal injuries and their use of imagery during the recovery process [13]. Ten athletes of various disciplines with different severity of injury had been interviewed once. Imagery was used for cognitive (e.g., learn rehabilitation exercise, motivational (e.g., goal setting) and healing reasons (e.g., distraction from pain)). Imagery was mainly performed during physiotherapy sessions prior to physical practice of an exercise. The authors described the content of athletes' imagery as vivid with both modes: visual and kinaesthetic, and with a positive performance. That included imagination of the athlete her/himself as a healthy individual performing in her/his sports discipline as successful as before the injury.

To create an international perspective of imagery use in supraelite athletes, MacIntyre and Moran interviewed twelve canoe-slalom competitors from Germany, Ireland, United States, and the United Kingdom [14]. Their purpose has been to investigate where, when, what, why, and how athletes use imagery. In addition, the authors were interested in the metacognitive control of imagery and asked athletes about their importance of imagery and why they have used this method. Results revealed different imagery directions (facilitative and debilitative) and strategies to overcome problems in activity sequences, for example, talk through a slalom course with the trainer.

So far, the existing framework on where, when, what, why, and how to use imagery from sports psychology has not been explored in brain-damaged individuals. The objective of this study was to investigate whether the imagery framework questions (where, when, what, why, and how) for MI can be applied in chronic-stage patients after stroke. The specific aims were (1) to evaluate whether the imagery framework questions (where, when, what, why, and how) established in mainly healthy and young students and athletes can be adopted by an older stroke population and (2) if new insights for the design of MI interventions can be obtained.

To address the aims mentioned above, a qualitative research method approach was used. This well-established research method originates from the social sciences. Obtained information from semistructured interviews, focus groups, or observations helps to understand and explore behavioural processes and generate hypotheses rather than testing experimental hypotheses. The participant's perspective and perceptions on unexplored concepts, diseases, or phenomena are the main focus of the investigation gathering textual information rather than numbers [15-18]. Applying semistructured interviews in the current investigation is most appropriate given the nature of the topic under investigation. In this approach, the interviewer could ask and explain the abstract construct of MI and giving the patients the opportunity to ask questions and check their correct understanding. The applied procedure offered the opportunity to acquire detailed information on the nature of patients' MI experiences, associations, MI training session elements (e.g., MI mode and state of eyes), and temporal parameters (e.g., duration of MI and number of MI trials).

\section{Methodology}

The goals of this work were approached using a frameworkbased qualitative research method, using semistructured interviews. Information reported in this paper, including 
reflexivity, study design, and data analysis, followed the qualitative research review guidelines (RATS) and the 32-item consolidated criteria list for reporting qualitative research (COREQ) [19, 20].

2.1. Study Design and Procedure. This qualitative investigation based on an explorative content analysis and was nested into a randomised control pilot trial (RCT) investigating two MI training approaches in patients after stroke. After giving written informed consent for the MI intervention trial, patients underwent two baseline measurement events, including MI ability assessments, balance evaluation, and assessment on independence of living. Following the baseline assessments, patients were randomised to one of three study groups. Patients allocated to either of the experimental groups (EG1, EG2) were asked whether they would like to participate in two semistructured interviews, one before and one after the two-week MI intervention period. Patients were informed about the procedure by the interviewer (CS) and received a second patient information sheet specifically developed for the interviews. The third group served as a control group. All three groups received standardised physiotherapy treatment focussing on balance. Patients MI training methods in EG1 and EG2 did not differ regarding content, duration, or frequency. The main difference can be seen in the integration approach of MI. One experimental group (EG1) embedded MI into physiotherapy. The second experimental group (EG2) added MI after the physiotherapy session. Patients of all groups had to practice one motor task physically "Going down, laying on the floor, and getting up again" in a standardised order. In EG1 and EG2, the motor task has also been practiced mentally. The control group listened to audio tapes with information related to stroke after physiotherapy. In total, treatment time was about 45 to 50 minutes for each group. A detailed study protocol is described elsewhere [21]. The study was implemented according to the Declaration of Helsinki and was approved by the ethics committee of the School of Health and Social Care of the Oxford Brookes University, Oxford (UK) and the responsible Swiss ethics committee (Aarau, Kanton Aargau, Switzerland, reference number 2008/077).

2.2. Interviewee Sampling and Data Saturation. Patients were recruited from both experimental groups (EG1, EG2) of the ongoing MI intervention trial with the following selection criteria: first ischemic or hemorrhagic stroke at least three months before study entry, being able to stand with or without a cane for at least 30 seconds on a normal hard floor, being able to walk 20 metres with or without a cane or an orthosis, older than 18 years, and score at least 20 in the Mini-Mental State Examination (MMSE), given written informed consent. Patients were excluded if they had joint replacements (knee, hip, and shoulder), movement-limiting pain in the upper or lower body evaluated with the 11-point visual analogue scale (VAS), limited range of motion in hip, knee, ankle joints, or toes, bodyweight exceeding $100 \mathrm{~kg}$, or having a compromised mental capacity to give written informed consent. Further restrictions resulted from the patients' ability to communicate and express thoughts, experiences, and feelings. Patients with severe speaking problems were not included. During the recruitment period between April 2009 and May 2010, eleven out of 26 patients fulfilled the selection criteria and agreed to participate in the semistructured individual interviews. The MI intervention study, which was closely connected to the semistructured interviews, determined the bounds for data saturation in patient interviews of this work. Saturation refers to the point at which the investigator has obtained sufficient information from the field [22].

2.3. Interview Setting. Interviews were conducted face to face between the patients and the first author (CS). Following written informed consent, interviews were conducted one to two hours before the first of six MI intervention sessions. The second interview took place after the last MI intervention session. To provide a high level of privacy and to avoid disturbances, all interviews took place in a separate treatment room of the rehabilitation centre. Patients were offered refreshments during the interview. Furthermore, patients could decide to not answer a question and to have breaks at any time during the interviews, if they wished to do so. Interviews were recorded with two redundant digital voice recorders to avoid loss of data. Patients and interviewer did not know each other before oral and written study information was given. After the first interview, CS worked with the patients during all six MI intervention sessions, which could have had an influence on the patients' reporting during the second interview.

2.4. Interview Guide and Procedure. A generic interview guide was developed for the first interview to account for different symptoms after stroke, for example, paresis level and psychological capacity. The interview guide was developed based on the interview guide published by MacIntyre and was divided into three parts [14]. Bearing in mind that MI could be very abstract to patients, the first part of the interview was not related to MI, but focused on the stroke event, patients' rehabilitation process including therapy experiences, and occurrence of falls. In the second interview part, patients were asked about their previous experiences and knowledge of MI. In the third interview part, a practical example of MI was performed, which included a sit-to-stand task. After performing this task twice physically, it was twice mentally practiced and again twice physically practiced. The aims of the simple and quick to perform practical example were (1) to provide patients, regardless of their previous MI experience, with MI experience, which helped them to describe MI content elements, for example, used MI mode (kinaesthetic, visual), perspective (internal, external), and imagined environment, and (2) to control for actual MI performance by recording the time (sec) needed to perform the example mentally and practically. The guide for the second interview only included questions regarding patients' experiences with MI during the previous two interventions weeks and a repetition of the practical example. In the final phase of both interviews, patients were asked to evaluate 
the interview, including questions on whether it was exhausting and how they liked it. Furthermore, patients' answers were summarised by the interviewer as a means of member checking, and patients had the opportunity to comment on, add to, or omit statements. The interview guides are provided in Table 1.

Three pilot interviews were conducted to familiarise with the interview procedure, test the interview guide, and practice the technical setup. No changes to the interview guide were deemed necessary after the pilots.

During and after the interviews, field notes and an interview report were written by the interviewer to describe important aspects of the interview (e.g., patients' mood, unexpected disturbances) as well as patients' gestures and behaviours. If leading questions emerged during the interview situation, answers were not included in the analysis. To verify the patient "yes" or "no" answers, another question with the opposite meaning was offered to the patient.

2.5. Data Analysis, Credibility, and Trustworthiness Procedures. Figure 1 provides an overview on all methodical steps from data recording to final analysis. All recorded interviews were transcribed verbatim (computer text document) by AS. Two researchers (KL, AH) involved in the assessments of the related MI intervention study checked the transcripts for a second time. Afterwards, all transcripts were checked for a third time by CS and copied into computer spread sheets for further analysis [23]. All verbatim-transcribed interviews were mailed to the patients for verification. Five of all mailed patients gave feedback and agreed with the reproduction.

The questions where, when, what, why, and how to perform MI were not considered for developing the coding scheme in the first line. With this approach, all emerging themes from the raw data could be captured. To address the quality item credibility, CS and AG developed the coding scheme jointly, based on three interviews before MI intervention and three interviews after MI intervention. The scheme was extended during further interview coding by CS. Each patient phrase or sentence was coded, where one sentence could contain information mapped to more than one code. At maximum, one sentence or phrase was matched to five codes. After coding was completed for all interviews by CS, AG applied the final coding scheme to code the MI-related part of one interview. This peercheck conformed to code cross-checking and evaluated the established codes [18]. Coding agreement was $80 \%$ (84 of 105 phrases), which was obtained before a consensus discussion. If both researchers (AG, CS) had not been able to agree on a decision (which was not the case in this investigation), a third researcher (JB) would have been consulted. In the summary and analysis step, only information related to MI was used. Patients' information was then transferred into a matrix to provide an overview on all patient statements matching one code. Based on this matrix, data were interpreted and allocated to the domains, categories, and subcategories of a hierarchy tree (FreeMind, version 0.8.1). The imagery framework questions (where, when, what, why, and how) represented the highest analysis level. Category names were derived from MI training session elements extracted in a systematic literature review on MI techniques [24]. Further domains and categories were added to the hierarchy tree to represent the complete range of patient information. Codes used in the coding scheme and their allocation to the respective domain are listed in Table 2.

To further increase the rigour of the analysis, two methodological details need to be considered. Firstly, all patients underwent two baseline measurement events of the MI intervention trial. The assessments on MI ability performed during the baseline measurement events supported patients' knowledge and interpretation of the MI construct. Secondly, during the interviews' practical MI example (sit-to-stand and back), patients and interviewer had to record the time needed with a stopwatch. These measurements helped to ensure a basic understanding and knowledge on the interview topic of interest for all patients. Furthermore, the triangulation of patients' interview data and assessment data helped to gain a broader picture of patients' MI understanding, but also to limit misinterpretation of interview data [18]. In general, at no time during the analysis were data modified or made to fit with the considered imagery framework (where, when, what, why, and how questions).

\section{Results}

3.1. Patients and Interviews. Important patient characteristics are displayed in Table 3. During all interviews, only patient and interviewer were present, except during the first interview where the patient's wife was present too (Pat. 32). In total, 20 interviews were conducted. Nine patients were interviewed twice, and two patients were interviewed before the MI intervention only due to patients' time constraints. Once during the first interview (Pat. 32), both voice recorders did not work properly, and about one-third of the interview could not be recorded. The duration of the interviews was averaged $38.4 \mathrm{~min}$ for the first and $22.3 \mathrm{~min}$ for the second interview. Patients' responses produced 216 lines of text (average) during the first interview, with only half (average of 106 lines) related to MI. During the second interview, patients' responses produced 124 lines of text (average) with 107 lines (average) that were MI related.

3.2. General Data Analysis Results. Information contributing to the patients' statements was based on experiences and knowledge acquired before the study, the practical example of MI performed during the interview, and on assumptions patients made after exercising the MI example. Example quotes were translated from German into English by CS and were double-checked by KL, who is a German native speaker but has proficient level in the use of English. The first two levels (domains and categories) of the hierarchy tree used in the data analysis are displayed in Figure 2 and Table 2.

\subsubsection{Where Using MI?}

The domain WHERE comprises two categories: (a) location and (b) position of the individual during MI. Both categories could be related to preparation for MI practice and consist 
TABLE 1: Interview guides.

Interview Interview part

The first focused on the stroke event, patients' rehabilitation process including therapy experiences and occurrence of falls.

The second interview part focussed on patients' previous experiences and knowledge of MI.

1 st interview

In the final phase, patients were asked to evaluate the interview, including questions on whether it was exhausting and how they liked it. Patients had the opportunity to comment on, add to, or omit statements.

The first part focused on questions

2nd interview regarding patients' experiences with MI during the previous two interventions weeks.
Interview questions

When did your stroke occur?

How did you recognize that you had a stroke? What symptoms did you have?

How did you feel when the stroke happened?

How do you feel today?

How was your recovery process?

What is your main problem at the moment?

How do you feel when you are walking?

Have you been falling since you had the stroke?

How does it feel to you to do motor imagery?

What do you associate with motor imagery?

(a) Did you know motor imagery before you have done the assessments?

(b) How did you get to know about motor imagery?

(c) When do you do motor imagery?

(d) How do you do motor imagery?

(e) What do you imagine?

(f) What kind of experiences have you made with motor imagery?

Was it easy to imagine the movement (standing up, sitting down)? If yes, why was it easy? If not, why was it not easy?

What exactly have you imagined?

How detailed was the movement?

What kind of surroundings/environment have you imagined?

What kind of perspective have you used (internal, external)?

What comes to your mind if you remember the imagination of the movement?

(a) What have you seen?

(b) What have you felt?

(c) What have you heard?

(d) What have you smelled?

Do you think that motor imagery could help patients after stroke during the recovery process? If yes, why?

When and how often would you do motor imagery?

Where would you do imagery?

What expectations do you have regarding the MI intervention during the next weeks?

What do you think about the interview?

Was the interview exhausting?

How do you feel now after the interview?

Would you like to add something?

How did you like the motor imagery intervention?

What do you think about motor imagery now?

Do you think motor imagery can help during the recovery process after a stroke?

How can motor imagery help during the recovery process?

Would you use motor imagery in the future to learn or improve a motor task?
(a) Why?
(b) When-how often?
(c) Where?
(d) What? 
TABle 1: Continued.

\begin{tabular}{|c|c|c|}
\hline Interview & Interview part & Interview questions \\
\hline & \multirow{12}{*}{$\begin{array}{l}\text { In the second part, the practical example } \\
\text { from the first interview was repeated. } \\
\text { Afterwards, patients were asked to describe } \\
\text { the content of the MI example. }\end{array}$} & Was it easy to imagine the movement? \\
\hline & & Why was it easy/not easy? \\
\hline & & What exactly have you imagined? \\
\hline & & How detailed was the movement? \\
\hline & & What kind of surroundings/environment have you imagined? \\
\hline & & What kind of perspective have you used? \\
\hline & & $\begin{array}{l}\text { What comes to your mind if you remember the imagination of the } \\
\text { movement? }\end{array}$ \\
\hline & & What have you seen? \\
\hline & & What have you felt? \\
\hline & & What have you heard? \\
\hline & & What have you smelled? \\
\hline & & $\begin{array}{l}\text { Did you think that motor imagery helped you to improve the motor } \\
\text { task? }\end{array}$ \\
\hline & Final phase & Please see first interview \\
\hline
\end{tabular}

\begin{tabular}{|l|l|l|l|l}
\hline Interviews 20 semistructured interviews \\
$\bullet$ Writing field notes + interview reports \\
$\bullet$ Only first author $(\mathrm{CS})$ involved
\end{tabular}

\begin{tabular}{|l|l|} 
Transcripts & $\begin{array}{l}\text { - Verbatim transcription of all interviews in word by AS } \\
\text { - Export of all transcripts into Excel } \\
\text { - Transcripts sent to all interviewees for member check }\end{array}$ \\
\hline
\end{tabular}

\begin{tabular}{|l|l|}
\hline Coding & $\begin{array}{l}\text { - Development of categorisation scheme based on six interviews by CS and AG } \\
\text { - Further interview categorisation and scheme adaptation by CS } \\
\text { - Evaluation of final categorisation scheme by AG based on one interview }\end{array}$ \\
\hline
\end{tabular}

\begin{tabular}{|l|l|}
\hline Summary & Data extraction (Excel) of all patient statements for each category by CS and AS \\
• Built hierarchy tree with mind map
\end{tabular}

Final data analysis tree

$$
\begin{aligned}
& \mathrm{CS}=\text { Corina Schuster } \\
& \mathrm{AS}=\text { Anne Scheidhauer } \\
& \mathrm{AG}=\text { Andrea Glässel }
\end{aligned}
$$

FIGURE 1: Data conduction, preparation, and analysis process.

of three subcategories each. In relation to location, three patients (Pat. 19, Pat. 38, and Pat. 6) talked about their home (living room, basement, garage, and garden), and one patient also specified the brightness of the location as being necessary (Pat. 19). He explicitly denied practising in the basement. Another male patient (Pat. 37), who used imagery during his marathon preparation before stroke onset, explained that he could practice MI anywhere, for example, in the train. For him, it was not necessary to calm down, neither to have a focussing moment before MI 
TABLE 2: Translated codes, categories, and domains for interview data analysis.

\begin{tabular}{|c|c|c|c|}
\hline & English code & English category & English domain \\
\hline \multirow{39}{*}{$\begin{array}{l}\text { Goals for intervention } \\
\text { period (upcoming } 2 \text { weeks) }\end{array}$} & MI usage & Expectation MI intervention & \multirow{39}{*}{$\begin{array}{l}\text { Patients' pre-study } \\
\text { knowledge, experience, and } \\
\text { understanding of imagery }\end{array}$} \\
\hline & MI example & & \\
\hline & MI example: grasp something & & \\
\hline & originating of MI & & \\
\hline & Preknowledge MI: yes—from sports & & \\
\hline & Preknowledge MI: yes—not from sports & & \\
\hline & Preknowledge MI: no & & \\
\hline & Practical performance motor task: grasp glass & & \\
\hline & $\begin{array}{l}\text { Practical performance motor task: grasp } \\
\text { something }\end{array}$ & & \\
\hline & Practical performance MI: to craft something & & \\
\hline & $\begin{array}{l}\text { Practical performance motor task: toe and } \\
\text { finger movements }\end{array}$ & of MI & \\
\hline & Practical performance motor task: movements & & \\
\hline & $\begin{array}{l}\text { Practical performance motor task: jogging } \\
\text { training }\end{array}$ & & \\
\hline & Practical performance since stroke: no & & \\
\hline & Preexperience MI: from assessments & & \\
\hline & Preexperience MI: operating sequence & & \\
\hline & preexperience MI: yes & & \\
\hline & Preexperience MI: yes- sport & & \\
\hline & Preexperience MI: thought about MI & & \\
\hline & Preexperience MI: no & & \\
\hline & Preexperience MI: did not help & & \\
\hline & Preexperience MI: disappointment & & \\
\hline & Preexperience: content MI & & \\
\hline & Meaning of MI & & \\
\hline & Reasoning for MI usage & & \\
\hline & Performing MI & & \\
\hline & Belief in MI: negative & \multirow{8}{*}{ Patients' understanding of MI } & \\
\hline & Belief in MI: positive & & \\
\hline & Belief in MI: sceptical & & \\
\hline & Hypothesis on MI requirements & & \\
\hline & Personal belief in MI & & \\
\hline & Requirement MI: quietness & & \\
\hline & $\begin{array}{l}\text { Preexperience: other psychological technique } \\
\text { (e.g., psyching up, activity planning) }\end{array}$ & & \\
\hline & $\begin{array}{l}\text { Preexperience: other psychological technique } \\
\text { (e.g., psyching up, activity planning) }\end{array}$ & & \\
\hline & Preexperience: autogenetic training & \multirow{5}{*}{$\begin{array}{l}\text { Other prestudy mental } \\
\text { imagery experiences }\end{array}$} & \\
\hline & Preexperience: content autogenetic training & & \\
\hline & Preexperience: dreaming & & \\
\hline & Performing MI: saying to yourself & & \\
\hline & $\begin{array}{l}\text { Preexperience: other psychological technique } \\
\text { (e.g., psyching up, activity planning) }\end{array}$ & & \\
\hline
\end{tabular}


TABLE 2: Continued.

\begin{tabular}{|c|c|c|c|}
\hline & English code & English category & English domain \\
\hline & $\begin{array}{l}\text { Assumption MI intervention period: not } \\
\text { helpful }\end{array}$ & \multirow{2}{*}{$\begin{array}{l}\text { Belief in MI after MI } \\
\text { intervention regarding } \\
\text { prestudy MI experiences }\end{array}$} & \\
\hline & Assumption MI intervention period & & \\
\hline \multirow{40}{*}{$\begin{array}{l}\text { MI content/reflecting on } \\
\text { sit-to-stand example }\end{array}$} & Performing MI: location & Location & \multirow{6}{*}{ Where } \\
\hline & Starting position MI & Position & \\
\hline & Assumption: starting position MI & Position & \\
\hline & Assumption: location MI & Location & \\
\hline & Performing MI: concentrating & Concentration & \\
\hline & Performing MI: concentrating no & Concentration & \\
\hline & MI: concentration difficulties & Concentration & \multirow[t]{16}{*}{ When } \\
\hline & Duration MI & Duration & \\
\hline & $\begin{array}{l}\text { Performing MI: simultaneously with other } \\
\text { activity }\end{array}$ & Situation & \\
\hline & Assumption: time of the day & Time of the day & \\
\hline & Reasoning for MI: MI content surroundings & Content MI of MI example & \\
\hline & Assumption: MI content & $\begin{array}{l}\text { Content of MI during MI } \\
\text { example }\end{array}$ & \\
\hline & MI content: stand up & Content of MI example & \\
\hline & MI content: motor task incomplete & Movement completeness & \\
\hline & MI content: motor task complete & Movement completeness & \\
\hline & MI content: motor task unclear & Movement completeness & \\
\hline & MI content: motor task like healthy people & Content of MI example & \\
\hline & MI content: imagine always the same & Content of MI example & \\
\hline & MI content: walking & Content of MI example & \\
\hline & MI content: person & Content of MI example & \\
\hline & MI content: see yourself & Content of MI on MI example & \\
\hline & MI content: sensation yes & Senses & \\
\hline & MI content: sensation no & Senses & \multirow[t]{18}{*}{ What } \\
\hline & MI content: sit-to-stand & Content of MI on MI example & \\
\hline & MI content: sit-to-stand (SS) complete & Movement completeness & \\
\hline & MI content: SS surroundings & Content of MI example & \\
\hline & MI content: imagine always the same & Content of MI example & \\
\hline & MI content: walking & Content of MI example & \\
\hline & MI content: person & Content of MI example & \\
\hline & MI content: see yourself & Content of MI on MI example & \\
\hline & MI content: sensation yes & Senses & \\
\hline & MI content: sensation no & Senses & \\
\hline & MI content: sit-to-stand & Content of MI on MI example & \\
\hline & MI content: sit-to-stand (SS) complete & Movement completeness & \\
\hline & MI content: SS surroundings & Content of MI example & \\
\hline & MI content: SS surroundings unclear & Content of MI example & \\
\hline & MI content: SS unclear & Content of MI example & \\
\hline & MI content: surroundings & Content of MI example & \\
\hline & MI content: surroundings light & Content of MI example & \\
\hline & MI content: surroundings nothing & Content of MI example & \\
\hline
\end{tabular}


Table 2: Continued.

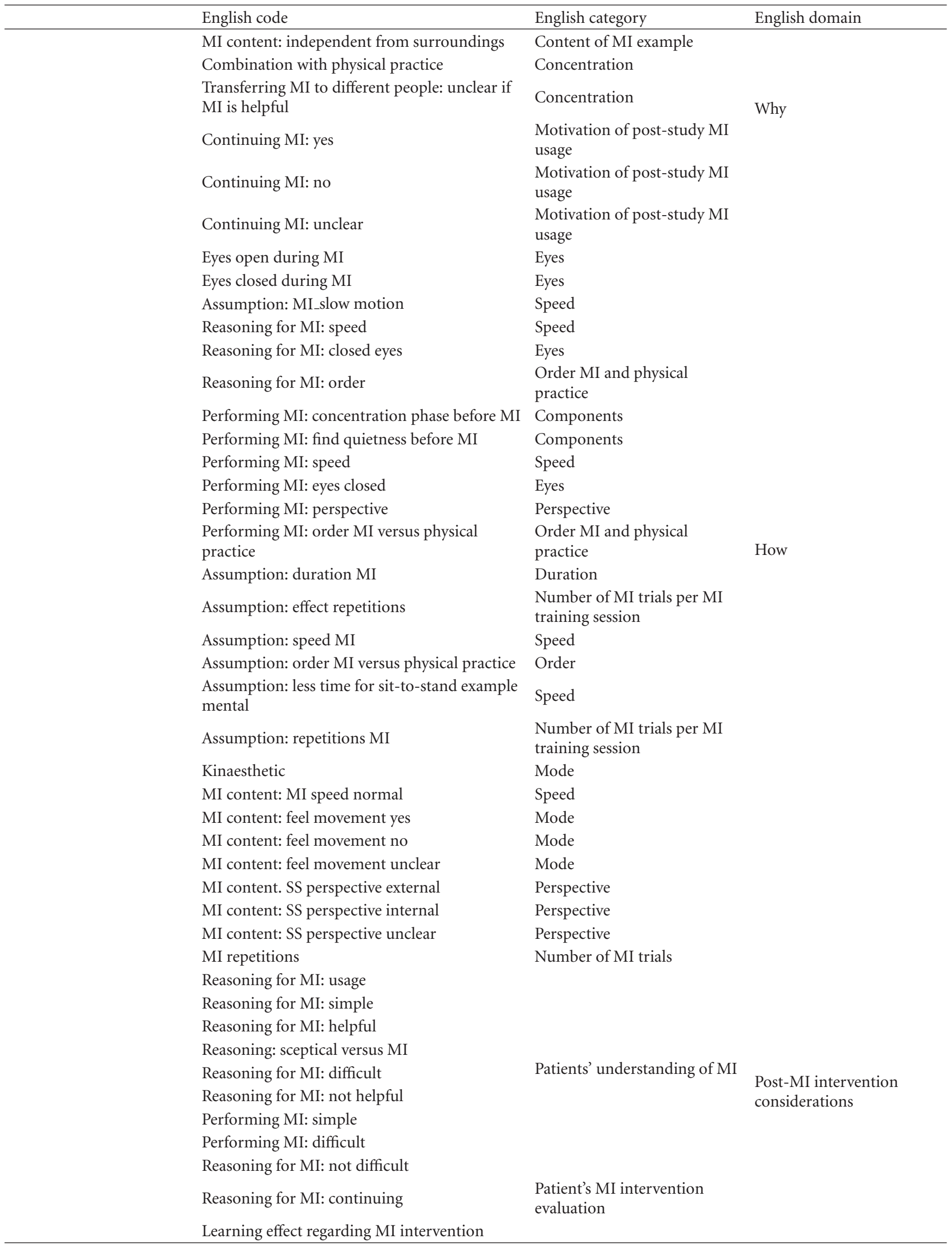


TABle 2: Continued.

\begin{tabular}{|c|c|c|}
\hline English code & English category & English domain \\
\hline $\begin{array}{l}\text { Learning effect regarding MI intervention: new } \\
\text { movement sequence }\end{array}$ & \multirow{7}{*}{$\begin{array}{l}\text { Patients' learning effect due to } \\
\text { MI intervention }\end{array}$} & \\
\hline Learning MI & & \\
\hline $\begin{array}{l}\text { Transferring MI to different movement } \\
\text { sequence: general }\end{array}$ & & \\
\hline $\begin{array}{l}\text { Transferring MI to different movement } \\
\text { sequence: walking }\end{array}$ & & \\
\hline $\begin{array}{l}\text { Transferring MI to different movement } \\
\text { sequence: fingers/hand }\end{array}$ & & \\
\hline $\begin{array}{l}\text { Transferring MI to different movement } \\
\text { sequence: no }\end{array}$ & & \\
\hline $\begin{array}{l}\text { Transferring MI to different movement } \\
\text { sequence: difficult }\end{array}$ & & \\
\hline MI content: get up from the floor & \multirow{3}{*}{ MI attributes/qualities } & \\
\hline $\begin{array}{l}\text { Transferring MI to different people: MI is } \\
\text { helpful }\end{array}$ & & \\
\hline $\begin{array}{l}\text { Transferring MI to different people: MI is not } \\
\text { helpful }\end{array}$ & & \\
\hline
\end{tabular}

TABle 3: Patient study characteristics.

\begin{tabular}{|c|c|c|c|c|c|c|c|c|c|c|c|c|c|c|c|}
\hline $\begin{array}{l}\text { Int. } \\
\text { number }\end{array}$ & $\begin{array}{l}\text { Patient } \\
\text { number }\end{array}$ & Age & Gender & Stroke & $\begin{array}{c}\text { Affected } \\
\text { brain } \\
\text { area }\end{array}$ & $\begin{array}{c}\text { Time since } \\
\text { stroke } \\
(y r s)\end{array}$ & MMSE & EBI & BBS & $\begin{array}{c}\text { KVIQ } \\
\text { vis. } \\
1 s t \\
\text { inter. }\end{array}$ & $\begin{array}{l}\text { KVIQ } \\
\text { kin. } \\
1 \text { st } \\
\text { int. }\end{array}$ & $\begin{array}{l}\text { Lines of } \\
\text { text 1st } \\
\text { int. }\end{array}$ & $\begin{array}{l}\text { Lines of } \\
\text { text } 2 \text { nd } \\
\text { int. }\end{array}$ & $\begin{array}{l}\text { Duration } \\
\text { in min } \\
\text { 1st int. }\end{array}$ & $\begin{array}{l}\text { Duration } \\
\text { in min } \\
\text { 2nd int. }\end{array}$ \\
\hline 1 & 6 & 61 & Female & CVI & Right & 1.3 & 28 & 62 & 43 & 48 & 48 & $234(102)$ & $163(147)$ & 39.1 & 23.4 \\
\hline 2 & 13 & 53 & Male & CVI & Left & 1.7 & 27 & 62 & 55 & 29 & 27 & $251(130)$ & $141(116)$ & 44.3 & 23.3 \\
\hline 3 & 15 & 31 & Female & ICB & Left & 2.6 & 27 & 62 & 48 & 35 & 25 & $230(73)$ & $58(56)$ & 30.0 & 12.0 \\
\hline 4 & 16 & 51 & Male & ICB & Right & 2.9 & 30 & 62 & 55 & 45 & 40 & $232(128)$ & 149 (104) & 33.5 & 27.4 \\
\hline 5 & 19 & 63 & Male & CVI & Bilateral & 2.6 & 25 & 63 & 55 & 43 & 46 & $258(123)$ & 97 (89) & 38.6 & 15.4 \\
\hline 6 & 21 & 82 & Female & CVI & Right & 6.4 & 27 & 63 & 45 & 30 & 50 & $131(53)$ & $113(108)$ & 37.2 & 22.2 \\
\hline 7 & 32 & 85 & Male & CVI & left & 3.8 & 26 & 62 & 55 & 45 & 43 & $110(53)^{*}$ & $121(89)$ & N/A* & 33.5 \\
\hline 8 & 33 & 54 & Male & CVI & Left & 3.3 & 28 & 64 & 56 & 50 & 10 & 223 (129) & $186(178)$ & 46.4 & 28.1 \\
\hline 9 & 37 & 45 & Male & CVI & Right & 3.4 & 23 & 57 & 49 & 50 & 50 & $362(193)$ & N/A & 47.1 & N/A \\
\hline 10 & 38 & 71 & Male & CVI & Left & 3.7 & 29 & 62 & 56 & 34 & 21 & 192 (109) & $91(78)$ & 33.1 & 15.2 \\
\hline 11 & 43 & 64 & Male & CVI & Right & 6.2 & 23 & 54 & 43 & 33 & 21 & $149(72)$ & N/A & 34.5 & N/A \\
\hline
\end{tabular}

Numbers in bold indicate patients who practiced a type of imagery before study participation. Numbers in brackets indicate the amount of lines of the complete interview particularly related to MI. Int. = interview, yrs = years, MMSE = Mini-Mental State Examination, EBI = extended Barthel index, KVIQ = Kinaesthetic and Visual Imagery Questionnaire, vis. = visual, kin $=$ kinaesthetic, $\min =$ minutes, N/A = not applicable, ${ }^{*}=$ the first interview of this patient could not be recorded completely due to technical problems.

practice, the imagery just started in his head without a trigger:

"Just like that. While sitting in a train, or tram, everywhere." (Pat. 37, 1st interview).

In relation to position taken for MI practice, seven patients identified a specific preferred position, two talked about a position related to the specific task to be imagined, and one patient spoke of other positions. The preferred position identified by patients can be related to the functional status of the individuals so that they felt safe and secure, for example, sitting or lying, or it might be related to the need to relax or "shut down" their thinking before starting MI practice. This contrasts with the changing task-specific position being adopted as preference, where the position mirrors the task starting position, for example, turning from supine lying to side lying.

"Basically, you could do that everywhere, don't you? In every, every position for sure. It depends on what you are going to do..... Sitting is a good starting position." (Pat. 16, 1st interview).

During the second interview, after the two-week MI intervention period and the experience of MI, location and 


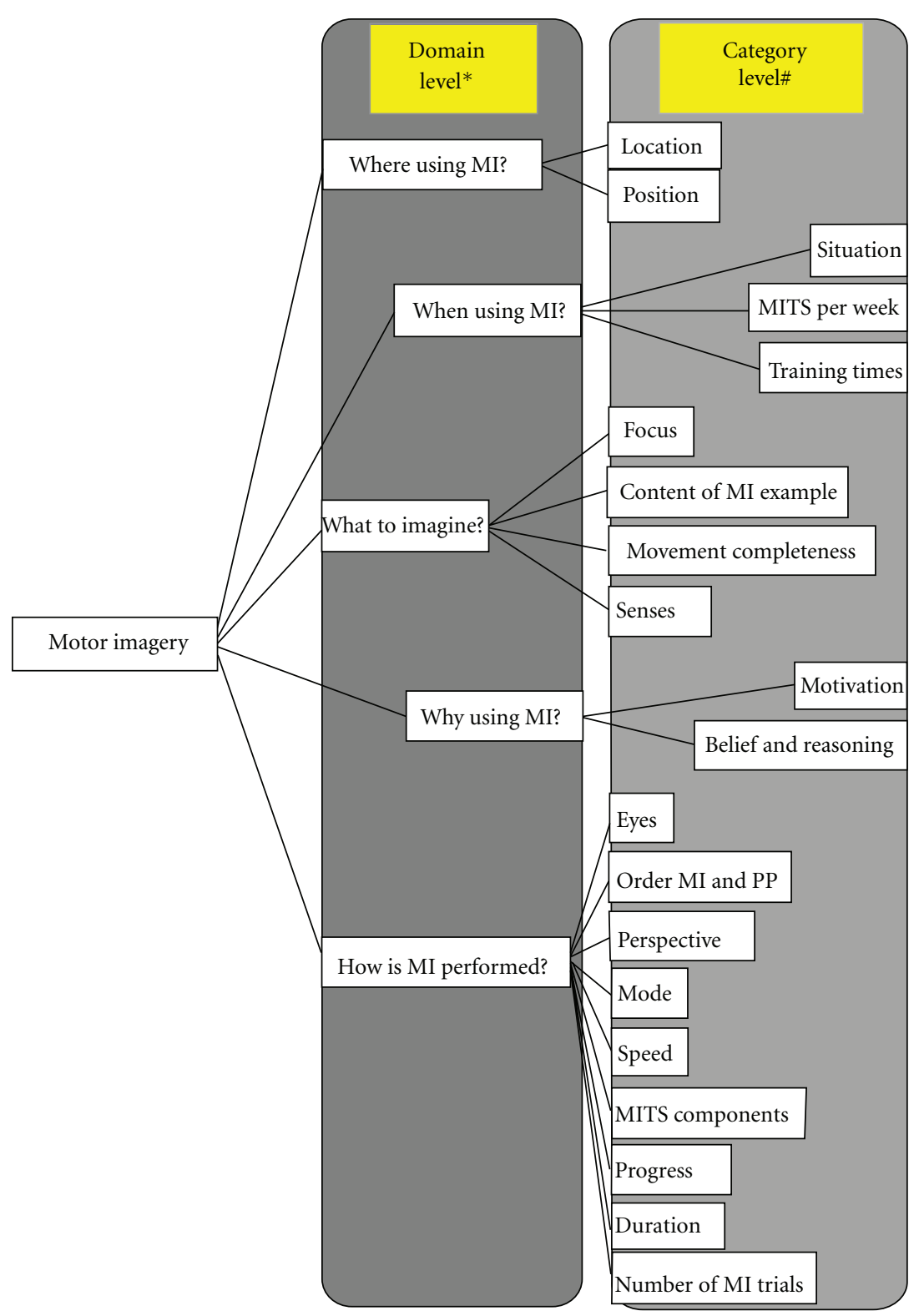

FIGURE 2: Final data analysis hierarchy tree. To remain readability, the level of the subcategories was not displayed but described in the text of the results section. \$ Patient information based on assumptions and on experiences after one practical MI example: sit-to-stand and back, $\mathrm{MI}=$ motor imagery. ${ }^{*}$ Domain level refers to the English domain column in Table 2. ${ }^{*}$ Category level refers to the English category column in Table 2.

position were again identified as the sole categories of the Where domain. However, brightness had not been identified as important this time, although a known environment was an additional idea voiced by patients as being useful. A known environment was preferred by patients as they would not be distracted by new things or having to explore a new environment first. They could focus solely on the task to be imagined.

\footnotetext{
"But,... in your usual environment, not where you have to absorb 100' 000 other things, and you have to remember them, haven't you?" (Pat. 16, 2nd interview).
}

The second interview data retained the subcategory identification of preferred position and task-specific position, indicating that after exposure to the MI technique, these domains remained important.

\subsubsection{When Using MI?}

Interview data relating to timing (WHEN) elicited three category themes: (a) situation (4 patients), (b) MI training session per week (2 patients), and (c) times of the day (4 patients).

In identifying when they carried out MI practice, 4 patients related this timing element to the situation or location (Where) category, showing that these domains were 
inter-linked. They talked about the need to concentrate on the MI task and therefore did not want to be disturbed by other tasks or noises (Pat. 32, Pat. 13, and Pat. 43). Some preferred a quiet environment or even wanted to be alone (Pat. 43, Pat. 6).

\section{"No, no, before [that] I have to sit down, close the eyes and simply, ehm, yes, calm myself down and actually concentrate on: now I stand up." (Pat. 13, 1st interview). \\ "Actually, when I'm alone at home and can fully concentrate." (Pat. 6, 1st interview).}

For three male patients, the When element corresponded to the number of MI training sessions per week indicating that MI training sessions should take place daily with MI repetitions at least 3 to maximum 10 times per day (Pat. 16, Pat. 43, and Pat. 13). Patients recommended short and frequent MI training sessions most likely as a consequence of their stroke, which let concentration emerge as a theme.

Relating to time of the day, some patients identified a preferred time of the day, which could be morning, afternoon, or evening, and for some the time of day related to tiredness, for example, when he/she cannot sleep during nights (Pat. 13, Pat. 6, and Pat. 38). A male patient, who used MI as marathon preparation before stroke onset, articulated that MI could be done at anytime of the day (Pat. 37). Furthermore, patients' diary entries from the MI intervention study link to the morning and evening times of the day for MI practice, in particular, when lying in bed before getting up and before falling asleep.

"Actually, [I can do it] always, when I take the time. But I think, it occupies the brain. And then, it does not make sense [to continue practicing MI] if you're too tired and you do it again." (Pat. 6, 1st interview).

During the second interview after the experience of using MI, two additional areas emerged in relation to timing of practice. Two patients considered that MI could be practiced while doing other activities that are automatic and which did not need focussed concentration, for example, while mowing, raking leafs, watching television, and cycling (Pat. 13; Pat. 33). This could obviously relate to increased confidence and competence in the MI technique, but also to the patient's motor function level. Furthermore, one male patient mentioned the necessity of a stable emotional and mental condition to practice MI (Pat. 13). After the second interview the category MI training sessions per week included the subcategory sporadic MI training in addition. The subcategory different time of the day reported anytime and spontaneously as two new MI training times.

\subsubsection{What to Imagine?}

In relation to WHAT patients imagined, interview data revealed four categories: (a) the related focus of a task to be imagined with subcategories motor related (four patients) and cognitive-related (four patients), (b) content of the imagined task with subcategories imagined surroundings (ten patients) and the imagined person (seven patients), (c) task completeness, concentrated on the accuracy and the complete performance of the task to be imagined (eleven patients), and (d) senses during $M I$ (nine patients).

MI had a cognitive related focus in imagined tasks before and after stroke onset. Before stroke onset, patients used imagery for marathon preparation, to organise staff, and work procedures (Pat. 37, Pat. 38, Pat. 33, and Pat. 19). After stroke onset, MI had mainly a motor related focus. Patients imagined simple single movements of fingers and toes, or trials to grasp and manipulate objects with the affected hand (Pat. 37, Pat. 19, and Pat. 16).

"And nothing happened, when you watched. Nothing happened. Only in my head I thought, yes, now I'm moving the toes. And the same with the fingers, did not it?" (Pat. 16, 1st interview).

Experiences gained through the practical example of MI during the interview allowed patients to generalise the MI technique for further use. Two patients mentioned a possible application of the MI technique in different motor tasks and particular, to stair climbing (Pat. 32, Pat. 37). In the patient's case, stair climbing is one of the most aspired movements. During the second interview, there was an increase in patients' perceptions of the possibility of options to apply the MI technique to other motor tasks. Furthermore, three patients had already started using MI to imagine problem movements as simple single motions, for example, move affected arm and hand, and as complex movements, for example, walking.

Concerning the category content of the imagined task, the described imagined surroundings (subcategory) related to the respective task (five patients), seeing things of the actual room (two patients), described a bright or dark environment (six patients), or simply nothing (two patients). The second subcategory person emerged from describing seeing themselves doing the task (five patients), or seeing an additional person in their imagery, for example, the therapist, who was in the room where they practised MI (Pat. 37, Pat. 21). Interestingly, patients always saw themselves as a healthy persons without any paresis or abnormality in their movements, supporting literature reports on athletes with musculoskeletal injuries. Similar to dreaming, MI might be understood as allowing individuals to be the "whole" self and may have therapeutic benefit in that psychological domain, but this remains untested.

The movement completeness category yielded subcategories complete and incomplete, where ten patients imagined the complete motor task with all phases. Differences were mentioned for individual phases of the imagining task. While start and finish positions were sharp and vivid (Pat. 38, Pat. 33), more unfocussed images of the movements were described in between. This was particularly evident in the patient, who used imagery as marathon preparation prior to stroke. 
"But the standing up, standing upright and sitting down again, that's what's inside my head. It stayed in my head better than the rest. The other phases were a little bit just a glimpse. Yes, where I got up and sat down, so the things inbetween it only was a glimpse." (Pat. 38, 1st interview).

The interview data revealed aspects of the individuals' awareness of their senses during MI practice. Whilst three patients had no sensory awareness during imagining, which could be related to the concentration needed for the motor task performance, many patients identified no awareness of smell or taste sensations (seven patients). However, two patients described awareness of the sounds related to the motor task, for example, creaking of the chair or shoes (Pat. 37, Pat. 38).

\subsubsection{Why Using MI?}

Patient data showed two major themes in relation to WHY patients were interested in MI: (a) motivation (4 patients) and (b) belief and reasoning. Both themes are based on patients' prestudy beliefs and after having performed a practical example of MI during the interview. Three major "motivations" were identified by patients (4 patients): (1) being able to integrate an affected limb in daily routines (Pat. 19), (2) ease physical practice with MI preparation (Pat. 19), and (3) practice difficult or problematic movements in general (Pat. 37, Pat. 38, and Pat. 33).

Clearly, patients hoped that this technique might improve their physical function. In relation to belief and reasoning, patients identified that it might help them to gain confidence in performing a movement (Pat. 21), that previous exposure to MI had shown that it is an effective technique (Pat. 33, Pat. 38, and Pat. 37), and that the rationale to learn MI is that they can use it on their own to practice impaired movements or action procedures (Pat. 16, Pat. 43, Pat. 15, and Pat. 19).

"Then you can learn it [MI], then you can do it [MI], and you realise that something is changing." (Pat. 43, 1st interview).

"It wasn't by far that way, but, ehm, the happiness was very great, wasn't it. And, yes, I tried it a lot, to move the fingers and all and watching and all, and when it only trembled a little bit, I was already happy, wasn't it." (Pat. 16, 1st interview).

"That I can do it [MI] myself at home." (Pat. 15, 1st interview).

Some patients, however, had opposing views and disbelief in the technique considered. One patient (Pat. 37) was very sceptical to MI use with paralysis, or on its own without physical practice. One patient went so far as to say "...because it is something stupid." (Pat. 32, 1st interview)

"You know, ..., you have to, yes, you have to do the tricks. You have to try, shift the weight. I always imagined it too. But it did not work because of it [MI]. If your limb is feebly, then it's feebly. Then you imagine it as long as you like." (Pat. 37, 1st interview).

There were three patients, who had no real opinion about MI. One of those patients mentioned that someone would have to remind him permanently to practice MI. Otherwise, he would forget to do so due to his memory problems since stroke onset.

Following exposure to the MI technique, new ideas emerged from patients in relation to its usage ( 3 patients).

"I think I will continue to do this [MI]. If I recognise that this [MI] will make me more flexible (agil). I will benefit from MI and I will benefit for sure. Now, I would say, it [MI] gives me more confidence. Now, it's inside the brain." (Pat. 21, 2nd interview).

\subsubsection{How Is MI Performed?}

The analysis on HOW patients conducted MI practice revealed a wide variety of elements.

(1) State of Eyes during MI. Six patients mentioned that they close their eyes during MI practice, some of them with the aim to improve concentration.

(2) Order of Physical Practice and MI Practice. Patients favoured MI trials "before" physical practice trials (2 patients). The advantage would be a better preparation for physical practice and therefore an easier physical practice performance.

(3) Perspective of Imagination. Patients used two perspective options during MI practice: internal perspective (4 patients) and external perspective ( 4 patients). In general, it is difficult for patients to describe the used perspective. Statements as "as I would stand in the corner over there" (Pat. 16, 1st interview) or "I saw myself as a person, as a whole person" (Pat. 16, 1st interview) indicated the external perspective. Here, the themes identified from the data support each other. The How and the What domains are linked together with their categories mode and senses.

(4) MI Mode. After performing the MI practice example during the first interview, five patients mentioned that they really felt the movement during imagination. This could be categorised as kinaesthetic MI and thus links with the What theme as described above.

(5) Duration of MI Trials Compared to Physical Practice Trials. The duration of MI trials was compared to physical practice trials in three subcategories: MI with a longer or shorter duration, and same duration like physical practice trials. A reason for these discrepancies regarding the trial duration of MI versus physical practice could be attributed to different levels of details imagined. 
(6) Components of an MI Training Session. During interviews, it became clear that some patients can start immediately with an MI trial, whereas others needed a short moment of concentration and focussing beforehand. Therefore, a category titled components of $M I$ was introduced.

(7) Progress in Performing MI. The oldest male patient, aged 85 (Pat. 32), mentioned that it would be helpful for him to start with a simple and short part of a motor task to imagine and add further steps after some consolidation. As this thought was confirmed by a second male patient during the second interview (Pat. 33), the category progress in performing MI was brought up.

(8) Duration of MI Practice. Related to the category time of the day when MI training is performed (domain When), it is the category duration. It describes the occasions where this category emerged with the number of MI trials below.

(9) Number of MI Trials. In general, patients reckoned that the training duration depends on the effort needed to practice MI (Pat. 6), but once a day seemed not enough. Patients suggested practicing MI several times (3-4) per day, with at least 2-3 subsequent MI trials (Pat. 13, Pat. 15, and Pat. 21). Both categories remained important in the second interviews. In particular, duration of MI practice was extended to of 4-6 minutes for 5-7 times per day (Pat. 13), organised in small breaks between working tasks. Furthermore, one male patient suggested a total MI intervention duration of up to six months to really learn the MI technique, aiming at using it for every daily movement or routine practice (Pat. 33).

3.2.6. Patients' Prestudy Knowledge, Experience, and Understanding of Imagery. A wide range of patients' prior exposure to MI was observed. Two patients reported active usage of MI, for example, during marathon preparation before stroke onset (Pat. 37), and to practice finger and toe movements after stroke onset (Pat. 16). Three patients had heard of MI or had seen athletes doing something what they interpreted as MI, in particular in ski racers just before their competition (Pat. 13, Pat. 6, and Pat. 33).

Four patients reported prestudy experiences with a type of mental imagery practice other than MI. One young female patient mentioned that she would dream, seeing herself walking without any impairment as she walked when she was healthy (Pat. 15). One middle-aged patient mentioned using autogenic training as stress-reducing technique (Pat. 13). Two males reported using a kind of self-talk or psyching-up technique to organise working procedures or for motivation purposes (Pat. 33, Pat. 13).

During the first interviews, patients offered various descriptions of what they understood or associated with the term MI, ranging from clear explanations to broad comments in both ways: positive and negative. "Well, it's something normal. Like I would think
about something different." (Pat. 33, 1st inter-
view).

"Surely close the eyes, imagine something and then practice." (Pat. 16, 1st interview).

"Well, something I cannot do at the moment, that I imagine it, like I'm able to do it. Then it's working actively. That I picture or visualise the whole procedure in my head." (Pat. 6, 1st interview).

"Well, one thinks it's something stupid." (Pat. 32, 1st interview).

3.2.7. Post-MI Intervention Considerations. After the MI intervention, patients still found it difficult to describe what they were doing during MI (Pat. 19, Pat. 32). However, most patients found that it was simple and easy to perform, not exhausting (Pat. 15, Pat. 6, Pat. 19, and Pat. 16), and became automatic and natural after a while. Additionally, patients had started using MI for movements that were problematic for them, for example, climbing stairs, using affected hand/ arm. Furthermore, six patients would recommend MI to other patients to practice depending on their mental capacity and their paresis level.

A minority of patients experienced MI during the intervention as difficult. Reasons were that they could not concentrate enough (Pat. 21), that they missed parts of the motor task to imagine and had to think about it/control all imagined details (Pat. 13, Pat. 32), and that physical practice trials were more easy to perform than MI trials of the same task (Pat. 32).

3.3. Patients' Learning Effects. The observed learning effects among patients were related to the interviews, practical example of MI, and the two- week MI intervention. Effects were related to the motor task, to $\mathrm{MI}$, and to mental abilities. Some patients identified an increased confidence in performing the motor task due to the several mental rehearsals. The improved MI ability was recognised by patients (Pat. 32, Pat. 13, Pat. 21, Pat. 33, and Pat. 15), including the ability to apply MI to other motor tasks (Pat. 13), and not needing quiet environments anymore (Pat. 13). Four patients attributed improved cognitive abilities to the MI practice, for instance, being able to concentrate faster and for a longer period (Pat. 33, Pat. 38), being more relaxed (Pat. 21), being more awake or alert (Pat. 33), doing less day dreaming, and being more motivated to do other activities (Pat. 13).

"Because I had the impression, it works my brain a little. I had the impression, if I'm doing this, then I'm more awake somehow. Had the impression, not only my circulation is trained, my brain also. And that's just how it is, I have the feeling, it works my brain too." (Pat. 33, 2nd interview).

3.4. Implications for Practice. Results from this research suggests that therapists may not expect patients to have 
experience with MI, but probably half of patients may have experience with some kind of mental practice, for example, autogenic training. Therefore, patients' previous mental practice knowledge should be evaluated before using $\mathrm{MI}$ in association with therapy sessions.

\subsection{Interview Observations}

Emotional Aspect. It is worth mentioning that patients actively reported on their personal and emotional situation during the interview. Even though, the patients' stroke event occurred some time ago, the description of the event, time in hospital, rehabilitation process, and retrospect became very emotional for several patients, for example, one female patient started crying.

MI-Related Aspect. It should be emphasised that patients saw themselves performing the motor task during MI. No patient described seeing herself/himself as a patient with impairments. All saw themselves as healthy as before stroke onset. Furthermore, related to the automatic MI, observed by some patients, performing MI of the motor task used in the intervention study started to occur suddenly in patients without conscious trigger.

Dissonance of Reporting. It is notable that one-third of the patients showed a dissonance in reporting. Their answers at the end of the MI-related part in the interviews could contradict answers from the beginning. This could be related to the insights on the abstract topic of MI gained during the interview and after having performed the practical example of MI.

\section{Discussion}

The established framework from sport psychology of where, when, what, why, and how MI is used was explored in patients after stroke in their chronic stage by conducting semistructured interviews. The applied procedure offered the opportunity to acquire detailed information on the nature of patients' MI experiences, associations, MI training session elements (e.g., MI mode and state of eyes), and temporal parameters (e.g., duration of MI and number of MI trials). Patients imagined themselves as healthy individuals without impairment. They did not focus on surroundings during MI practice, and they reported to use positive imagery only. MI became automatic after the two-week MI intervention, and patients did not need focussed concentration and quietness as mentioned before the MI intervention.

Munroe and colleagues used a hierarchy with "where" as first level, "when" as second level, and "why" and "what" as third level [10]. In contrast, this investigation allocated the questions "where," "when," "what," "why," and "how" to the same hierarchy level, which was also used in the publications of Driediger et al. [13] and Nordin and Cumming [12].

Based on the results of Kosslyn et al., one may expect more patients having reporting the prior use of an imagery type used [9]. Two arguments could explain the different result: study patients in this current work were explicitly asked about knowledge and experiences of MI, not mental practice in general. Furthermore, we did not interview young, healthy students, but patients after stroke in the chronic stage of the disease.

\subsection{Where Using MI?}

Patients after stroke liked to practice MI at home or when alone, which is in line with athletes with musculoskeletal injuries in Driediger et al.'s investigation [13]. Furthermore, athletes practiced MI mainly during physiotherapy sessions before finishing an exercise, whereas stroke patients did not mention using MI during therapy at al. In the current analysis, location and position were identified as WHERE categories, whereas Nordin and Cumming and Driediger et al. did only focus on "location" $[12,13]$.

\subsection{When Using MI?}

Similar to athletes with musculoskeletal injuries, patients considered that MI could be practiced while doing other activities that are automatic, and which did not need their focussed concentration, for example, watching television, driving a car [13]. This insight was reported by patients during the second interview only. We assume that the delayed insight could be caused by the MI training during the intervention period, where patients gained MI knowledge, practice, and experience. A categorisation of the WHEN domain by situation, MI training session per week, and training time of the day was not reported by Driediger et al. for athletes.

\subsection{What to Imagine?}

Driediger and colleagues did not describe the domain HOW as MI performed [13]. Therefore, their domain WHAT incorporated five categories including session, effectiveness, nature, surroundings, and imagery type. The latter one was classified to the domain How in the current investigation. Driediger et al.'s category session described the length of the MI practice between 5 and 30 seconds for athletes with musculoskeletal injuries. In contrast, patients after stroke several MI practice sessions per day with a length of up to 15 minutes were accounted in the category duration (domain HOW). Whereas athletes in category nature reported "positive" and "negative" imagery, patients mentioned after stroke "positive imagery" only. Both groups indicated seeing themselves as healthy individuals or athletes possessing their preinjury motor function and competition level. Additionally, surroundings during MI practice did not play an important role for athletes with musculoskeletal injuries and patients after stroke, which could be due to focusing on the healing process in athletes and the MI learning process in patients.

"Type" in the study of Driediger et al. included reporting on MI perspective and vividness of imagery [13]. Both categories were classified to the domain HOW in the current investigation. 


\subsection{Why Using MI?}

Paivio's framework on effects of imagery on human motor performance influenced Driediger et al's classification of WHY doing athletes with musculoskeletal injuries MI [11, 13]. Driediger et al., [13] devised cognitive-specific imagery as a help to perform rehabilitation exercises. MI was before and simultaneously executed with physical practice aiming at skill enhancement in athletes with musculoskeletal injuries. "Cognitive general" imagery was used to maintain the ability to carry out activities associated with their sport. "Motivational-specific" imagery was used to visualise goal and related activities and to maintain motivation by imagining full recovery and future competitions. "Motivational general" (arousal and mastery) was used to continue rehabilitation, even in painful conditions and to keep mentally tough. In athletes with musculoskeletal injuries, motivational imagery was not used to enhance confidence. In the current investigation, patients after stroke rarely used MI before the MI intervention study. Therefore, an allocation to "Motivational general" based on the traditional framework is difficult. Patients' reasons to use imagery included gaining selfconfidence to perform the motor task, easier physical practice performance after MI, and being more alert. These indications are in line with the results of the review from Feltz and Landers [25]. The authors emphasised that with the help of imagery, the performer is better prepared for the following action, through shorter reaction times, lower sensory threshold, appropriate tension levels, focused attention, and an increase of muscle action potentials. Driediger and colleagues also mentioned three more categories of the domain WHY: healing with images of the physiological recovery process, pain management, and injury prevention. None of them could be explored in patients after stroke [13].

\subsection{How Is MI Performed?}

Munroe et al.'s and Driediger et al.'s reports did not use the HOW domain $[10,13]$. In the current investigation, nine categories were identified in this domain, from which two were included in the What domain by Driediger et al. (MI type, MI perspective) [13]. In this current work, "HOW" aims to describe characteristics for the MI intervention design, which is contradictory to the "HOW" domain identified by Nordin and Cumming [12]. Their "HOW" domain included three categories related to triggers that help to obtain images, to relate MI to symbolic images, and to design graded levels of images. The latter can be interpreted as compounding a basic visualisation and adding up more details of the image and sensation. However, we believe that the MI experience in patients after stroke cannot be compared to athletes' MI experience. Therefore, an in-depth description of their MI trigger and MI acquirement cannot be expected. Often patients reported that they had to start MI of the motor task by themselves. After the MI intervention, MI started automatically regardless the patients' current situation, location, or activity.

\subsection{Linkage of Domains}

During the data analysis, it became clear that several considered domains are related.

WHAT and HOW. Although How comprises categories describing the design of an MI training, it also contains the categories perspective and MI mode that could be associated with the category senses in the domain What. Munroe et al. and Driediger et al. did not describe a How domain $[10,13]$. However, Driediger and colleagues did define "perspective" and "mode" under the domain What, but termed mode as type.

WHEN and WHERE. Patients information for the domain When was closely related to the situation or location in the domain Where

WHEN, WHAT, and HOW. For the domain When patients reported the number of MI training sessions per week, number of MI trials. Agreements for concentration (What) were mentioned and short but frequent MI training sessions recommended (How).

\subsection{Limitations}

It could be argued that the nested study design limited the diversity of patient information gained and biased patient selection. However, all eleven patients showed a wide age range from 31 to 85 years, different motor function level, and time periods from stroke onset to study entry (1.3 to 6.2 years). Furthermore, Guest et al. showed in their study with 60 in-depth interviews that data saturation occurred within the first twelve interviews already, suggesting that the sample considered in this investigation is sufficient [26]. Moreover, participating in the related pilot RCT provided more detailed data on patients MI ability and offered the opportunity to confirm patients' statements from the first interview, for example, regarding MI content, with responses from the second interview.

The interviewer's MI knowledge and her function as therapist in the related MI intervention study could have influenced formulating and asking questions in an attempt to cue certain answers and information. We assume that patient responses were not influenced by the interviewer as patients expressed their negative MI experiences honestly during the second interviews.

No category related to MI ability or vividness of imagery could be confirmed based on the patients' interview data. Nevertheless, a link to the category movement completeness could be drawn, which classifies incompletely or completely seen movements. However, we believe that the interviewed patients did not have the detailed knowledge on this particular MI characteristic after the short MI intervention compared to continuously MI-trained athletes.

Despite constrains in qualitative research involving patients with different levels of speaking impairments, which could limit the richness and depth of responses, it is 
important to apply qualitative techniques, as confirmed by the results obtained in this investigation.

\section{Conclusion}

Until now the imagery framework has been explored in various sports disciplines, but not in patients after stroke, who are not trained in using MI routinely. MI understanding and usage differs between athletes and patients after stroke. It is essential to determine MI understanding and ability in stroke patients, in order to design tailored MI interventions. In this work, the framework on where, when, what, why, and how MI is used has been adopted from sports psychology and applied to organise information gained in semistructured patient interviews. It became clear that MI is not established in patients after stroke. MI was not used to support motor function recovery. In rare cases, MI appeared spontaneously and was used for simple movements, for example, grasping. Patients related MI to a mental technique aiming at practicing movements that are not possible at the moment or gain confidence in difficult movements. Furthermore, patients imagined themselves as healthy individuals without impairment. They did not focus on surroundings during MI practice, and they reported to use positive imagery only. After MI training, patients became more flexible regarding their location and position during MI practice. In most cases, MI became automatic after the intervention, and patients did not need focussed concentration and quietness as mentioned in the first interview. MI use is clearly underresearched in stroke rehabilitation. Future MI intervention studies for patients after stroke should include an evaluation of patients' MI ability and an MI familiarisation session to learn essential MI training session elements and their characteristics, for example, MI perspective, MI mode. Furthermore, MI interventions should start with simple motor tasks and less MI trials repetitions. After a consolidation phase, MI trial repetitions could be increased, and more complex motor tasks could be imagined.

\section{Funding}

The research project was partially funded by the Gottfried und Julia Bangerter-Rhyner Foundation.

\section{Acknowledgments}

The authors would like to thank all patients for participating in both interviews and reviewing all interview transcripts. Furthermore, they would like to thank Karin Lutz and Andrea Heinrichs for double and triple check of the transcribed data and patients' quote translation. They are thankful to Dr. Oliver Amft, who critically reviewed and commented on an earlier version of the paper.

\section{References}

[1] S. M. Braun, A. J. Beurskens, P. J. Borm, T. Schack, and D. T. Wade, "The effects of mental practice in stroke rehabilitation: a systematic review," Archives of Physical Medicine and Rehabilitation, vol. 87, no. 6, pp. 842-852, 2006.

[2] A. Zimmermann-Schlatter, C. Schuster, M. A. Puhan, E. Siekierka, and J. Steurer, "Efficacy of motor imagery in poststroke rehabilitation: a systematic review," Journal of NeuroEngineering and Rehabilitation, vol. 5, article 8, 2008.

[3] H. Ziemainz, S. Hendrich, M. Schleinkofer, and K. Pfeifer, "The application of mental training in the rehabilitation of stroke patients - review and calculating effect sizes," Physikalische Medizin Rehabilitationsmedizin Kurortmedizin, vol. 18, no. 4, pp. 198-202, 2008.

[4] L. S. M. Calayan and J. M. R. Dizon, "A systematic review on the effectiveness of mental practice with motor imagery in the neurologic rehabilitation of stroke patients," The Internet Journal of Allied Health Sciences and Practice, vol. 7, no. 2, 2009.

[5] J. Decety and J. Grezes, "Neural mechanisms subserving the perception of human actions," Trends in Cognitive Sciences, vol. 3, no. 5, pp. 172-178, 1999.

[6] E. Y. Yoo and B. I. Chung, "The effect of visual feedback plus mental practice on symmetrical weight-bearing training in people with hemiparesis," Clinical Rehabilitation, vol. 20, no. 5, pp. 388-397, 2006.

[7] G. Yue and K. J. Cole, "Strength increases from the motor program: comparison of training with maximal voluntary and imagined muscle contractions," Journal of Neurophysiology, vol. 67, no. 5, pp. 1114-1123, 1992.

[8] K. A. Martin and C. R. Hall, "Using mental imagery to enhance intrinsic motivation," Journal of Sport \& Exercise Psychology, vol. 17, no. 1, pp. 54-69, 1995.

[9] S. M. Kosslyn, C. Seger, J. R. Pani, and L. A. Hillger, "When is imagery used in everyday life? A diary study," Journal of Mental Imagery, vol. 14, pp. 131-152, 1990.

[10] K. J. Munroe, P. R. Giacobbi, C. Hall, and R. S. Weinberg, "The four Ws of imagery use: where, when, why, and what," Sport Psychologist, vol. 14, no. 2, pp. 119-137, 2000.

[11] A. Paivio, "Cognitive and motivational functions of imagery in human performance," Canadian Journal of Applied Sport Sciences, vol. 10, no. 4, pp. 22S-28S, 1985.

[12] S. M. Nordin and J. Cumming, "Professional dancers describe their imagery: where, when, what, why, and how," Sport Psychologist, vol. 19, no. 4, pp. 395-416, 2005.

[13] M. Driediger, C. Hall, and N. Callow, "Imagery use by injured athletes: a qualitative analysis," Journal of Sports Sciences, vol. 24, no. 3, pp. 261-271, 2006.

[14] T. E. MacIntyre and A. P. Moran, "A qualitative investigation of imagery use and meta-imagery processes among elite canoeslalom competitors," Journal of Imagery Research in Sport and Physical Activity, vol. 2, no. 1, pp. 1-23, 2007.

[15] C. McKevitt, J. Redfern, F. Mold, and C. Wolfe, "Qualitative studies of stroke: a systematic review," Stroke, vol. 35, no. 6, pp. 1499-1505, 2004.

[16] T. K. Kvien and T. Heiberg, "Patient perspective in outcome assessments-perceptions or something more?" Journal of Rheumatology, vol. 30, no. 4, pp. 873-876, 2003.

[17] U. Flick, Designing Qualitative Research, vol. 1 of The SAGE Qualitative Research Kit, Sage, London, UK, 2007.

[18] G. R. Gibbs, Analysing Qualitative Data, vol. 6 of The SAGE Qualitative Research Kit, Sage, London, UK, 2007.

[19] J. P. Clark, How to Peer Review a Qualitative Manuscript, BMJ Books, London, UK, 2nd edition, 2003.

[20] A. Tong, P. Sainsbury, and J. Craig, "Consolidated criteria for reporting qualitative research (COREQ): a 32-item checklist for interviews and focus groups," International Journal for Quality in Health Care, vol. 19, no. 6, pp. 349-357, 2007. 
[21] C. Schuster, J. Butler, B. Andrews, U. Kischka, and T. Ettlin, "Comparison of embedded and added motor imagery training in patients after stroke: study protocol of a randomised controlled pilot trial using a mixed methods approach," Trials, vol. 10, article 97, 2009.

[22] R. A. Krueger and M. A. Casey, Focus Groups: A Practical Guide for Applied Research, Sage, Thousand Oaks, Calif, USA, 3rd edition, 2000.

[23] D. Z. Meyer and L. M. Avery, "Excel as a qualitative data analysis tool," Field Methods, vol. 21, no. 1, pp. 91-112, 2009.

[24] C. Schuster, R. Hilfiker, O. Amft et al., "Best practice for motor imagery: a systematic literature review on motor imagery training elements in five different disciplines," BMC Medicine, vol. 9, article 75, 2011.

[25] D. L. Feltz and D. M. Landers, "The effects of mental practice on motor skill learning and performance: a meta-analysis," Journal of Sport \& Exercise Psychology, vol. 5, pp. 25-57, 1983.

[26] G. Guest, A. Bunce, and L. Johnson, "How many interviews are enough?” Field Methods, vol. 18, no. 1, pp. 59-82, 2006. 


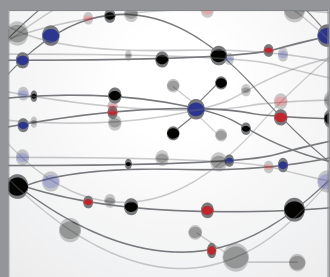

The Scientific World Journal
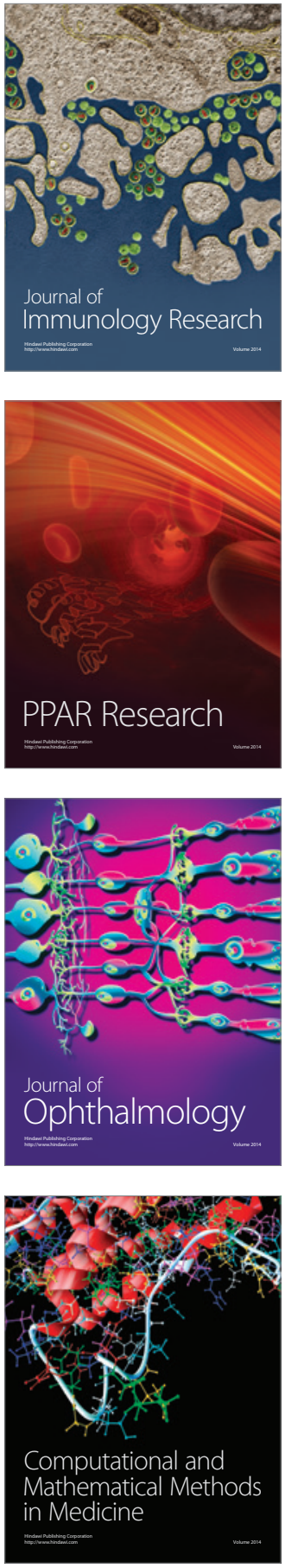

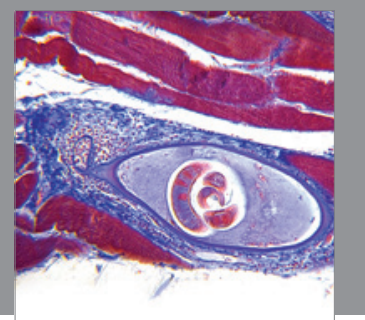

Gastroenterology

Research and Practice
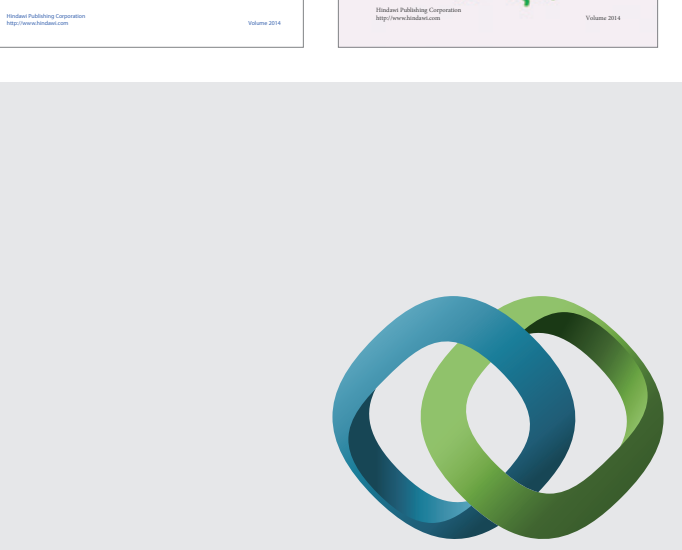

\section{Hindawi}

Submit your manuscripts at

http://www.hindawi.com
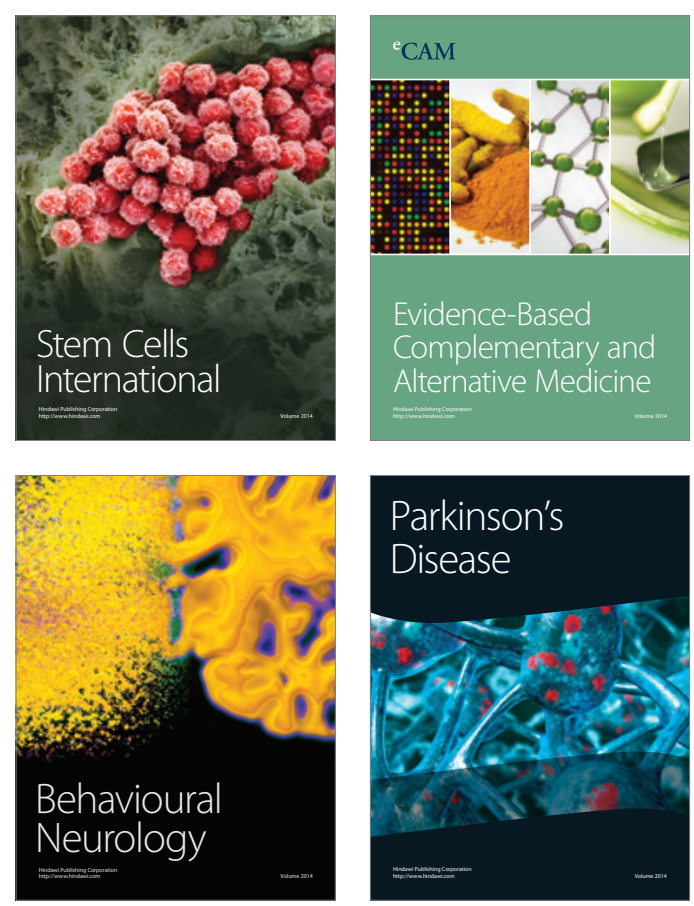

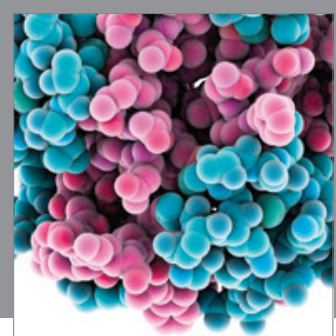

Journal of
Diabetes Research

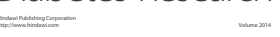

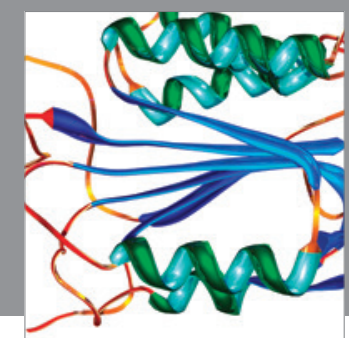

Disease Markers
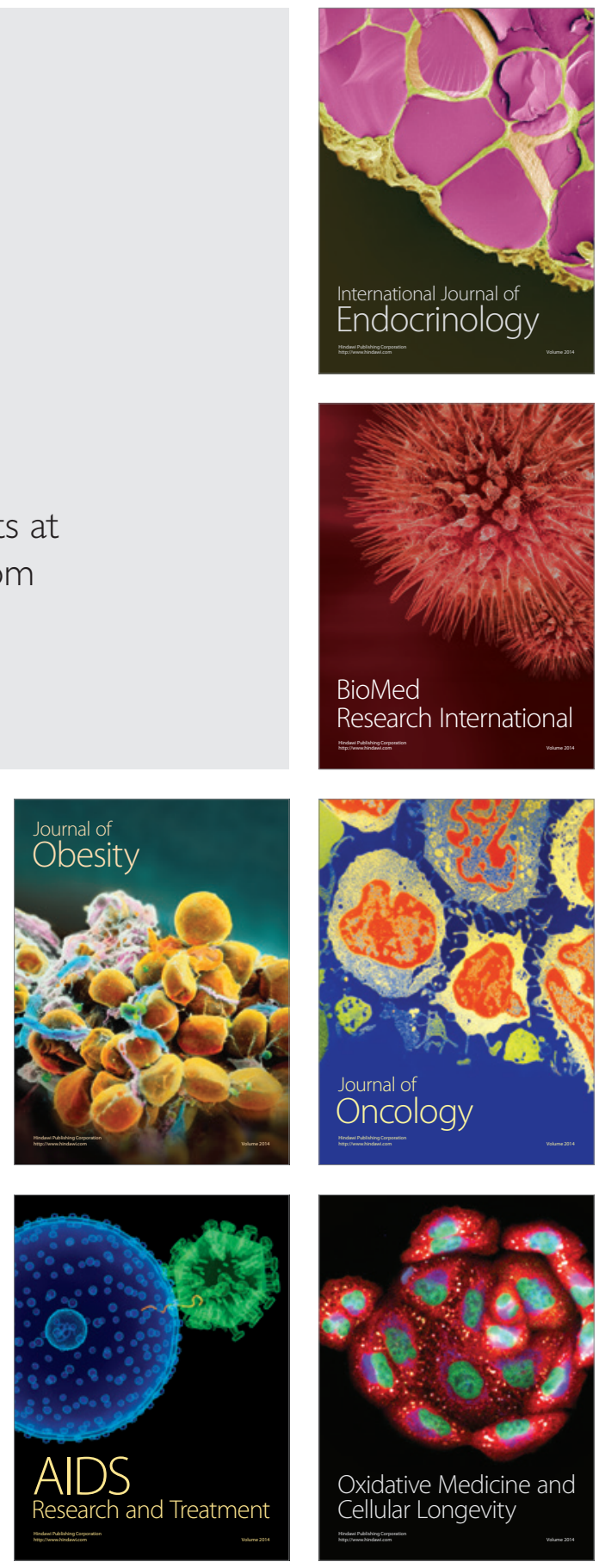